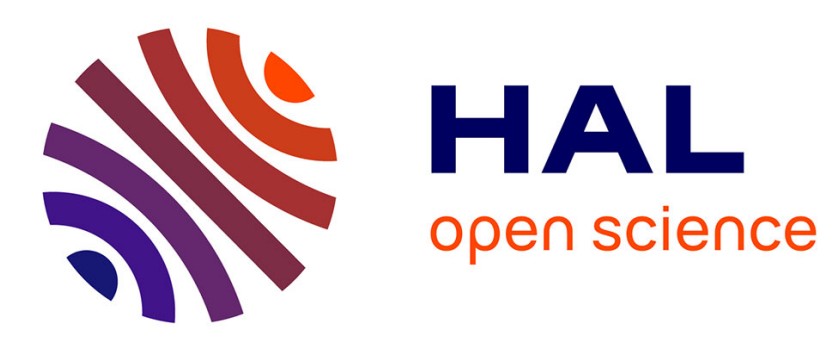

\title{
A New Soft Load Shedding: Power System Stability with Contribution from Consumer
}

Diana Craciun, Stefan Ichim, Yvon Besanger

\section{To cite this version:}

Diana Craciun, Stefan Ichim, Yvon Besanger. A New Soft Load Shedding: Power System Stability with Contribution from Consumer. IEEE PowerTech 2009, Jun 2009, Bucarest, Romania. pp.IEEE Catalog Number CFP09815-CRD ISBN: 978-1-4244-2235-7. hal-00402844

\section{HAL Id: hal-00402844 https://hal.science/hal-00402844}

Submitted on 8 Jul 2009

HAL is a multi-disciplinary open access archive for the deposit and dissemination of scientific research documents, whether they are published or not. The documents may come from teaching and research institutions in France or abroad, or from public or private research centers.
L'archive ouverte pluridisciplinaire HAL, est destinée au dépôt et à la diffusion de documents scientifiques de niveau recherche, publiés ou non, émanant des établissements d'enseignement et de recherche français ou étrangers, des laboratoires publics ou privés. 


\title{
A New Soft Load Shedding: Power System Stability with Contribution from Consumers
}

\author{
D. Craciun, S. Ichim, Y. Bésanger, Senior Member, IEEE
}

\begin{abstract}
The safe operation of electrical power systems is an ongoing problem. Despite the existing defense lines in the different electrical systems, they are not immune to widespread incidents leading to tripping of most consumers. In the defense plans against these major incidents, selective load shedding (LS) even optimized (but brutal), is the last resort before total blackout. This paper proposes a new concept of residential consumers "soft" load shedding (SLS). Its originality lies within the fact that it takes only a fraction of the consumers' power, even if the effort is spread over a larger number. It therefore seeks to avoid the plunge into darkness.
\end{abstract}

Index terms--Black-out, Intelligent home, Residential consumer, Smart grids, Soft load shedding, Voltage stability.

\section{INTRODUCTION}

$I_{\text {in }}^{\mathrm{N}}$ $\mathrm{N}$ electrical power systems, all means of production operate in parallel and supply simultaneously all consumers. Meanwhile, like in all complex structures, if precautions are not considered, it could present certain fragility.

To increase the service quality to their costumers, electricity companies established certain planning and operating rules, so that the power system is able to face at each instant the current uncertainties, such as loss of one or several transmission or power production equipments (N-1 criteria) [1]. These rules do not cover all contingencies and do not offer the guarantee that the power system is completely protected against major incidents [2]. However, these incidents that take place in transmission or interconnection electrical networks have important socio-economic impacts within the regions or countries where they occur. A generalized black-out, at country scale, completely paralyses it during the necessary time needed to restore the normal functioning of the power system, which can take up to several days [3]. An example of this kind of incident is represented by the Italian black-out that took place in September 2003 [4], [5].

In this context, we can imagine a defense system based on an intelligent SLS. The objective of this study is to radically change the shedding concept used today in critical situations. In the current defense plans, LS is used as the ultimate strategy because it consists of putting a number of consumers in the

D. Craciun and Y. Bésanger are with the National Polytechnic Institute of Grenoble, France (e-mail: diana.craciun@g2elab.inpg.fr, yvon.besanger@g2elab.inpg.fr).

S. Ichim, is with Polytechnic University of Bucharest, Romania. (e-mail: ichimstefan@yahoo.com). dark, in a manual or automatic manner, according to the dynamics of the incident in question. The goal is to stop the black-out propagation into the rest of the network. Moreover, LS is not necessarily optimized, although there are a number of methods for this in the literature [6]. In order to realize the intelligent SLS the using of the "intelligent" home concept [7] was considered.

If we consider that in the near future, homes, business centers and industries can be equipped with this kind of intelligent system, if we consider also that there will later exist management structures of integrated networks (concept of smart grids), then we can imagine that in case of an incident in the transmission power system, the defense system calculates an optimal LS (which node and which power do we need to shed to contain the incident?). Then the SLS is achieved after being validated by the distribution power systems management center. It can also be performed in a more preventive manner than the classic LS, without being afraid of taking the wrong decision, given the limited impact on consumers and this will no longer be an ultimate strategy. It can also resolve problems related to the identification of a critical situation (level of criticality of the incident) that determines if the LS should be triggered or not. The intelligent LS may also be considered as an ancillary service of consumers for the power systems operator and could represent the object of a contract.

The outline of this paper is organized as follows: in section II, the LS principle will be described; the concept of the "intelligent" home will be the subject of the third section of the paper followed by the setting up of the simulation tool and by its results. Lastly, the conclusions will be presented.

\section{LOAD SHEDDING PRINCIPLE}

Nowadays, LS represents the final solution used to avoid voltage collapse or overloads cascade on a wide area electrical network after all other resources have been exhausted. For this study, LS has been used as the primary means to prevent voltage collapse. So, instead of brutal LS, SLS should be used. It will help prevent a major incident and will also keep consumers powered during curative actions for situations of this nature.

Detection of a low voltage level in the transmission power system may indicate a reactive power lack that could endanger the system stability [8]. As a consequence, it will be necessary to relieve a part of the load to maintain stability. This shedding takes place when a disturbance of the system happens and 
leads to voltage drops below a certain threshold for a predefined time interval. We can then expect the voltage stabilization. Loads with high reactive power absorption are more suitable to shed in order to prevent a voltage collapse. On the other hand, if the electrical network does not dispose of sufficient reactive power, the voltage collapse could rapidly occur and shedding may not have enough time to restore the situation. It is the responsibility of the transmission system operator (TSO) to maintain at all times the balance between the supplied and the requested power. To do that, the TSO must ensure a management that takes into account the uncertainties that may occur (e.g.: damage of a generating unit, a higher consumption than the expected one) [9].

The consumption shedding that is proposed in this paper does not consist in cutting a part of consumers, but cutting a percentage of the load of every consumer in order to maintain the voltage level of the power system. The proposed concept aims the local detection by the TSO of the low voltage level followed by a local automatic reduction of consumption. The TSO communicates with the distribution system operator (DSO), which performs optimal LS in the intelligent home consumer-type. The goal is to stop voltage drop when voltage level exceeds a preset threshold.

The proposed LS based on the above described concept is simple and takes into account the following hypotheses [10]:

1) $5 \%$ of the load will be shed if the voltage exceeds with $10 \%$ the lowest normal voltage level within a 2 second time interval;

2) $5 \%$ of the load will be shed if the voltage exceeds with $8 \%$ the lowest normal voltage within a 3 second time interval.

Under voltage LS is an economical solution (or partial solution) to the voltage stability challenges facing electric utilities. The aim of this work was to achieve a demonstrator which, depending on the voltage level, automatically sheds the load in order to assure the power system stability. The innovative element of this study is that LS is realized at the intelligent homes level, which can help prevent serious incidents like black-outs (see Fig. 1).

This LS is realized by using intelligent homes (described in the $3^{\text {rd }}$ section of this paper), which is based on the home

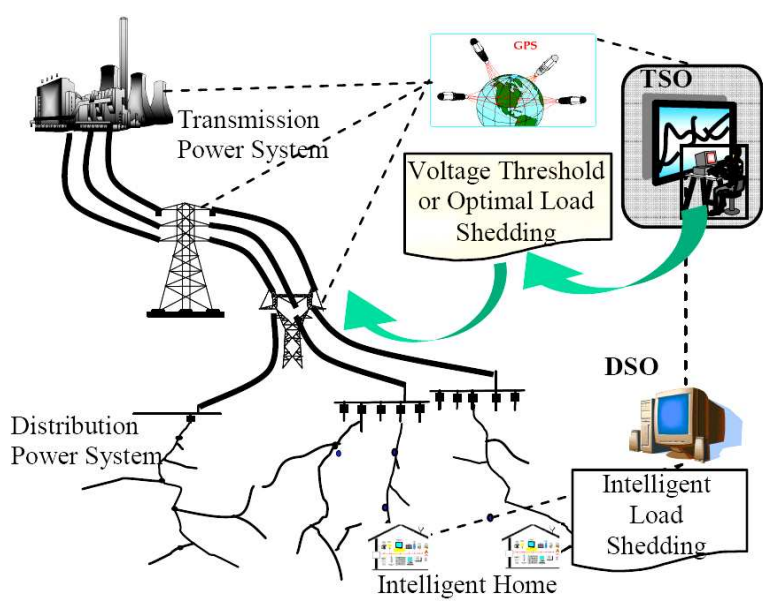

Fig. 1. Diagram of threshold voltage or optimal load shedding. automation concept. Nevertheless, the first version of the proposed demonstrator uses the "soft" non-optimal LS concept which includes the "intelligent" home concept. Further works will include optimal LS.

\section{INTELLIGENT HOME CONCEPT}

The "intelligent" home [7] is an intelligent energy management system in housing. Its goal is to adapt the electrical energy consumption to power availability while maximizing the user's comfort (e.g.: thermal comfort). It also allows the energy consumption optimization by avoiding the peak consumption by shifting the power of certain loads (e.g.: delay the washing machine), by reducing the power supplied to certain loads (e.g.: lighting), or by temporarily disconnecting some others. An anticipation mechanism based on external data (exterior temperature, resources, etc.), internal data (user instructions) and habits learning of users allows a consumption forecast that helps avoiding peak consumption. A protection mechanism inside the "intelligent" home can activate or deactivate major loads. A local command can adjust the temperature around a threshold calculated by an anticipation mechanism, or adjust the supplied power depending on the equipment category: equipment that can be delayed or commuted, but not interrupted; equipment that can be interrupted (thermal equipments). This system exploits the natural capacity of energy storage of the thermal environments and quantifies the thermal comfort of the user.

"Intelligent" home (not designed for that initially), can be used to carry out LS, without affecting the consumer comfort. Nevertheless, the consumer is in a more comfortable situation than a brutal power cut generated by conventional LS.

Load management can be achieved through direct and indirect solutions. The direct load management (command) is based on technological measures and on loads control by directly switching on or off the equipment (Fig. 2). The comfort can be maintained without ensuring continuity of electricity supply. Modern communication technologies are used today in order to apply load control strategies. Load management is based on indirect economic measures. Different rates and evaluation mechanisms are used to encourage the client to optimize the load. For example, there are the different fees for non interruptible loads and for component loads.

The main objectives of load management system are to reduce consumption, to reduce load peaks and to transfer consumption from the high fee period to a lower fee period.

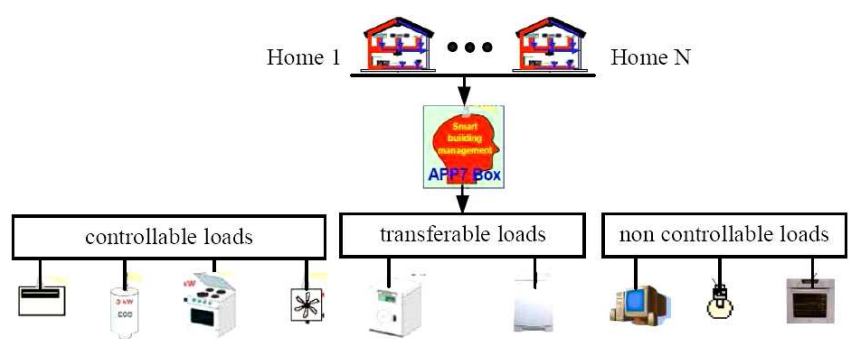

Fig. 2. Intelligent home concept. 
The most used methods for load management are LS or load switch on, consumption transfer, temporary programming and locally distributed generation [7].

LS can temporarily relieve an electrical installation in order to limit the requested power. This solution can be intelligently used for the load optimal management using shedding techniques. The equipments which are targeted by this solution are domestic units, commercial air conditioning units and central heating. The main objective is to use the thermal inertia offered by these equipments in order to reduce their consumption by maintaining a minimum level of comfort. The principle and operation of the regulator proposed for radiators is presented in Fig. 3. The implementation of the proposed method is the same for air conditioners, but their operation must be reversed compared to that of heating. Thereafter, the method is applied for radiators management in homes, or air conditioners management in homes or in hotels. The proposed method takes into account the system operator information, the actual load behavior and the weather conditions.

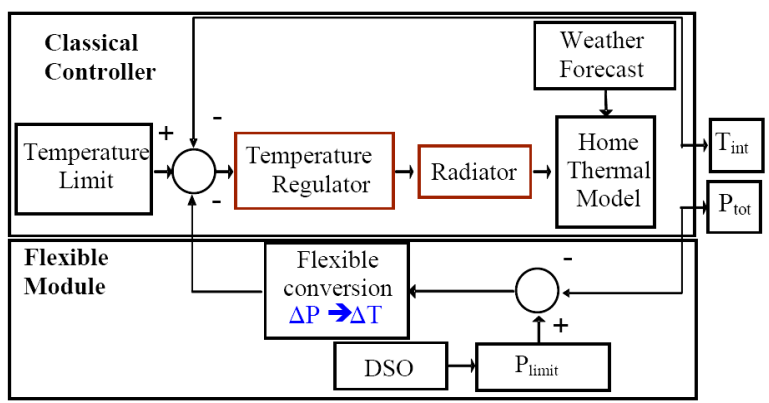

Fig. 3. Intelligent home model.

The flexible module of the "intelligent" home model behaves according to the difference between the total requested power and the power limit (or allowed power) on the basis of a closed loop as follows:

1) measure of the total demanded power;

2) comparison between the measured power and the power limit value sent by the DSO;

3) flexible conversion of the difference between the two power values into a temperature difference;

4) limit value correction according to this difference;

5) action on the radiator operation.

This type of regulation allows, whenever is possible, to ensure thermal comfort while limiting the peak of total consumption to a predetermined level.

The next section describes the realization of a simulation tool, which models the SLS concept based on the behavioral model of the "intelligent" home.

\section{SeTting UP THE Simulation TOOL}

The simulation tool represents a software co-simulation between EUROSTAG [11], Matlab Simulink [12] and Matlab [13]. EUROSTAG is the software which permits the modeling and the dynamic simulation of a considered power system. Matlab Simulink represents the support for the intelligent home management system (IHMS) and Matlab fulfills the role of the data management system and facilitates the interface between the IHMS and the power system as shown in Fig. 6, at the end of this section.

The first step toward the concept validation was the choice of a power system benchmark. The Western Systems Coordinating Council (WSCC) [14] transmission power system was chosen for carrying out the validation tests, and modeled in EUROSTAG. The chosen power system consists of 29 generators $\left(\mathrm{P}_{\mathrm{Gtotal}}=57 \mathrm{GW}, \mathrm{Q}_{\mathrm{Gtotal}}=19 \mathrm{GVAr}\right)$ and 173 nodes (71 are consumer nodes). Fig. 4 shows the simplified scheme of WSCC. This scheme offers information regarding the voltage levels of the power system, its geographical regions (the power system is divided in five zones) and the names of all generating units.

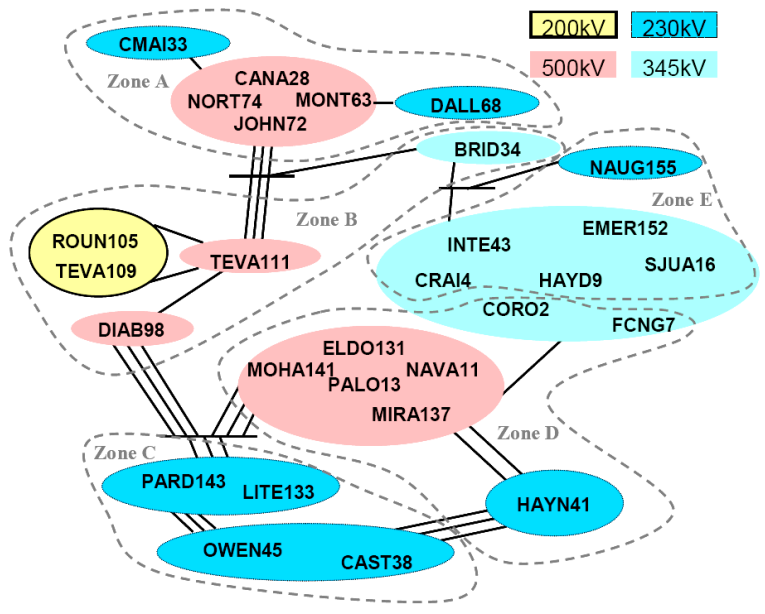

Fig. 4. WSCC benchmark scheme.

In order to test the IHMS, two distribution networks corresponding to a rural and an urban type respectively, were attached to the initial WSCC benchmark, in zone B. The total power consumption of the rural network is $\mathrm{P}=5.94 \mathrm{MW}$, respectively $\mathrm{Q}=1.19 \mathrm{MVAr}$ and the total power consumption of the urban network is $\mathrm{P}=19.87 \mathrm{MW}$, respectively $\mathrm{Q}=3.99$ MVAr. Each load is considered to consist of $43 \%$ residential type and $57 \%$ industrial and tertiary type. The load evolution follows a real load curve [15], on a total period of 24 hours. The most significant period for this study is between 16:00 and 19:00 (Fig. 5). In this time interval, the load suffers a sudden increase, which may influence the power system evolution during the dynamic simulation.

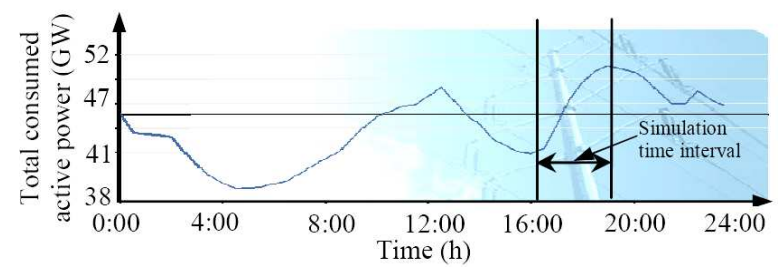

Fig. 5. The considered load curve [15].

Three consumer nodes from each distribution network have been chosen as representative for this study. Each node consists in a different number of consumers/homes and thus, has a different load value (Table I). The objective is to study the influence of the network evolution, of the loads number 
and characteristics on the IHMS consumption governing manner. In each selected node, three types of "intelligent" homes were connected. Each home has two rooms equipped with different rated power equipments. The load types within the three types of homes are shown in Table I.

TABLE I

LOADS WITHIN THE THREE TYPES OF “INTELLIGENT" HOMES

\begin{tabular}{|l|c|c|c|}
\hline & Home Type 1 & Home Type 2 & Home Type 3 \\
\hline P radiator 1 $(\mathrm{kW})$ & 5 & 2.5 & 2 \\
\hline P radiator 2 $(\mathrm{kW})$ & 5 & 3.5 & 2.5 \\
\hline P load 1 $(\mathrm{kW})$ & 2 & 1.5 & 1 \\
\hline P load 2 $(\mathrm{kW})$ & 3 & 2.5 & 2 \\
\hline P load 3 $(\mathrm{kW})$ & 1 & 1 & 0.5 \\
\hline Total power $(\mathrm{kW})$ & 16 & 11 & 8 \\
\hline Home rated power $(\mathrm{kW})$ & 12 & 9 & 6 \\
\hline
\end{tabular}

${ }^{a}$ other loads: lighting, television, washing-machine, air conditioning.

The loads within each home are considered resistive, as the main power consumers are represented by radiators. The number and the nature of the equipments from each home is the same. Only the rated power of each device is different in order to obtain a different evolution of home consumption.

The radiators are placed in identical rooms (with the same thermal inertia) in order to study their capacity to maintain the room's temperature at an acceptable value for the consumer. These loads are interruptible devices, equipped with thermostats, which govern their operation depending on the room temperature and on the available power for each home.

The operation of the load management model which governs the radiators is described in [7]. The other loads in the home are non-interruptible, and operate during specific time intervals, unlike the radiators which have no operational time restraints. As the other loads are not interruptible, and have their own operation time interval, the operation of the radiator which equips each room of the home will be represented as result. Their operation depends on two constraints: the room temperature and the home's available power.

The radiator's governor model has as input parameter the home exterior temperature. The temperature of each room is calculated in accordance with the chosen thermal characteristics (thermal inertia). If the temperature of the room drops below $19{ }^{\circ} \mathrm{C}$ or increases above $21{ }^{\circ} \mathrm{C}$, the radiator thermostat commands it to switch on, respectively, to switch off. When the total power consumption for each home exceeds the rated power, the IHMS will decrease the temperature superior value threshold of the thermostat by 1.5 degrees and thus, it will trigger between $19^{\circ} \mathrm{C}$ and $19.5^{\circ} \mathrm{C}$, as an attempt to maintain the consumer's level of comfort. Another constraint for the radiators operation is represented by the home's available power. Each home has an imposed power limit for its total consumption which cannot be exceeded. Only the LS procedure can modify this setting, as described in [9].

After having all data concerning the IHMS and after creating the foundation for the proposed study, the next step in the demonstrator validation process is to create a scenario that will produce a black-out in the chosen power system (reference study case). The IHMS and the LS system implemented on the
WSCC adapted power system represent the support of a comparison with the reference study case. Fig. 6 shows the synoptic scheme of the demonstrator.

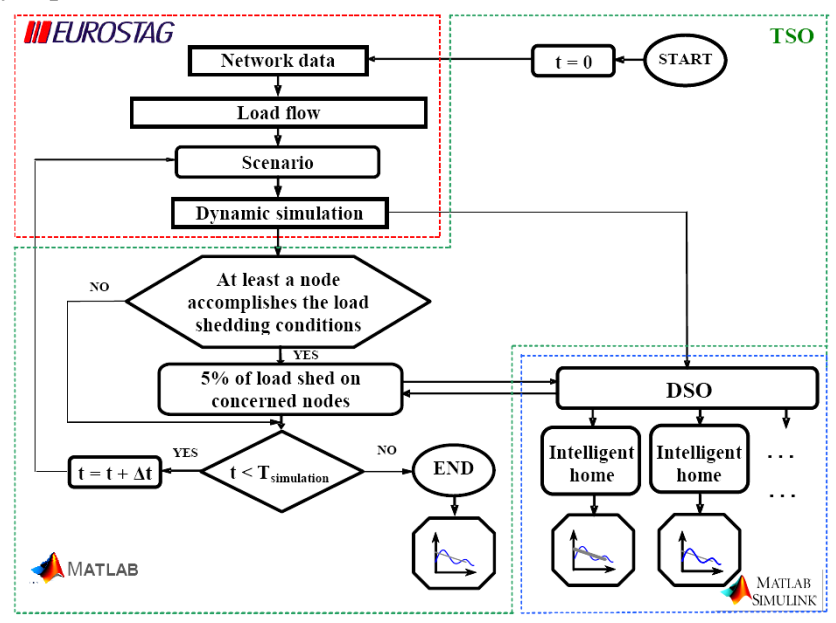

Fig. 6. Demonstrator's synoptic scheme.

\section{SiMULATION RESULTS}

For the WSCC power system to reach collapse, there must be at least a triggering event, followed by a sequence of cascading events. Each event has a weakening effect of the network, which will finally produce a partial or even a total black-out.

In order to create the environment for the validation study, a voltage collapse combined with cascading overloads will achieve a general system breakdown (with slow dynamics). Hazardous events, such as the loss of an interconnection or the triggering of a generating unit, lead to voltage drop over the WSCC transmission power system. This will generate a voltage drop within the two distribution power systems connected in zone B. Furthermore, the transformers in the transmission power system, modify their transformation ratios in order to maintain the voltage level. The modification of onload tap changers leads to a voltage level increase in the distribution electrical networks and to a voltage level drop in the transmission electrical network. As consequence, a massive reactive power injection will provoke cascading overloads, which eventually will lead towards black-out.

Firstly, the electrical network operation in case of black-out occurrence on an area is considered, before usual curative measures are to be taken by the electrical network operators. This situation provides the reference case for the proposed study. The next step is to simulate the network operation in case of the SLS algorithm implementation combined with the IHMS. The final step consists in comparing the results of the two simulations in order to show the efficiency of the new innovative procedure of LS in presence of IHMS.

The moment zero of the simulation corresponds to the beginning of the simulation period shown in Fig. 5.

The temporally triggering events of the black-out scenario are:

1) shut down of a major power generator (TEVA 111 - see Fig. 4) from zone B at $t=100 \mathrm{~s}$. 
2) increase, in addition of the already existing load curve, of the active power consumption by $5 \%$, and of the reactive power consumption by $10 \%$ over area B at $t=360 \mathrm{~s}$.

As a reaction of the electrical network, commutations of taps of the transformer on-load tap changers, which link area B with other areas, occurred and also of the transformers which link the $500 \mathrm{kV}$ and the $200 \mathrm{kV}$ electrical network of area B. The successive tap changes increased the voltage in the lower voltage network level to the detriment of the voltage in the higher voltage zone of the electrical network. The voltage drop on the higher voltage side led to an increase of reactive power flows over the lines, which caused cascading overloads.

On the contrary, by applying the SLS in the considered scenario, the voltage level is restored between its limits. An example of the voltage evolution of a consumer node from zone B is shown in Fig. 7. This load is a WSCC power system major consumer (an aggregation of several distribution power systems) that shed seventeen times and had the greatest contribution of reactive power in the shedding process. Its shedding has a great impact on the voltage of all the nodes in its neighborhood.

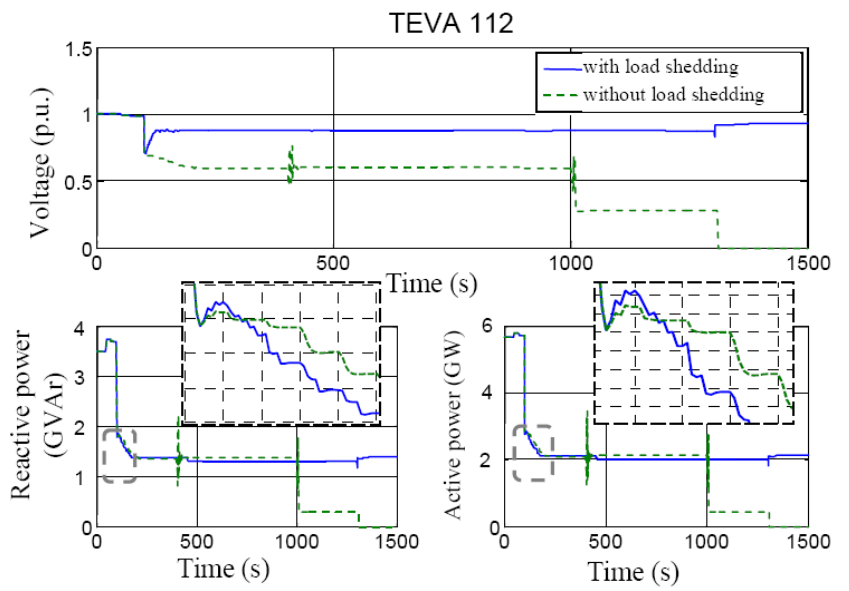

Fig. 7. Example of voltage and power evolution of a zone B major consumer node.

To illustrate the voltage evolution and power consumption of the "intelligent" homes in the two distribution networks, two nodes were chosen: a node from the rural distribution network (N70, which does not participate at LS) and a node from the urban distribution network (NU30, which participates at the LS) (see Fig. 8).

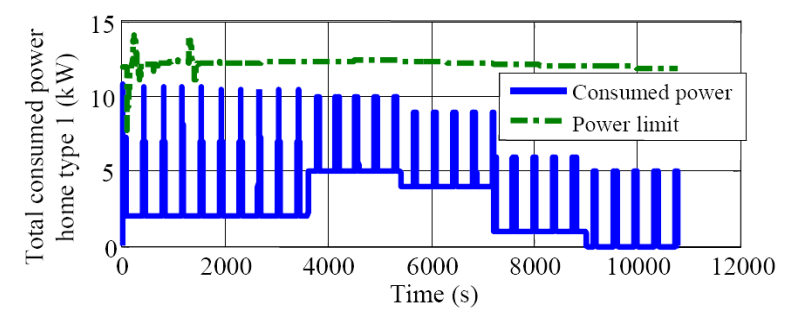

Fig. 8. Load behaviour of node N70.

At each node, three types of homes with different consumptions are connected. The rest of the node's load consists in an agglomeration of these three types of consumers and other loads, which do not concern this study. Fig. 8 shows the behavior of the node belonging to the rural distribution power system connected to WSCC transmission power system. The dashed-line graph represents the evolution of node N70 admissible power limit. The full-line graph is the temporally evolution of the home's active power consumption. The home's power consumption does not exceed the admissible level during the considered simulation time interval, due to the load management system. The overloading cascades in the transmission system only affect the imposed power limit. At the beginning of the simulation period, a strong variation of the consumed power occurred. This variation took place because the rooms temperature is below the limit of $19^{\circ} \mathrm{C}$ which provokes the two radiators operating together (to increase the temperature), at the same time with a noninterruptible load of the home (lighting). During the peak energy consumption period (between 3600s and 5400s), the load management system succeeds in maintaining the room temperature between $19^{\circ} \mathrm{C}$ and $21^{\circ} \mathrm{C}$, at the expense of an intense demand over radiators' thermostats, which will trigger the two radiators rapidly. During this time interval, two of the non-interruptible loads operate, thus leaving enough available power for only one radiator. The load management system checks the home's total available power (by comparing the power consumption admissible limit with the home's actual power demand), and then will allow (or not) the thermostat to trigger the operation of the radiator. The thermal comfort of the consumer will be maintained through the two radiators operation and also through the home thermal inertia.

To conclude, the consumers connected to node N70 are properly supplied with electric energy during this time interval, due to the load management system implemented at each home and the SLS procedure applied to the neighboring nodes.

Fig. 9 shows the behavior of a node belonging to the urban distribution network, which participates at the load-relieving of the network. The power consumption of the home never exceeds the admissible limit, due to the IHMS implemented in the home, which governs the loads. The available power is "shared" between the two radiators and the other three noninterruptible loads in the home. Node NU30 has shed four times: at 102s, 104s, 106s and 108s as seen in Fig. 9. Node NU30's voltage level in restored to normal after the SLS and the action of IHMS, which did not allow the power consumption to exceed the admissible limit. The SLS procedure adjusts the power consumption admissible limit, by

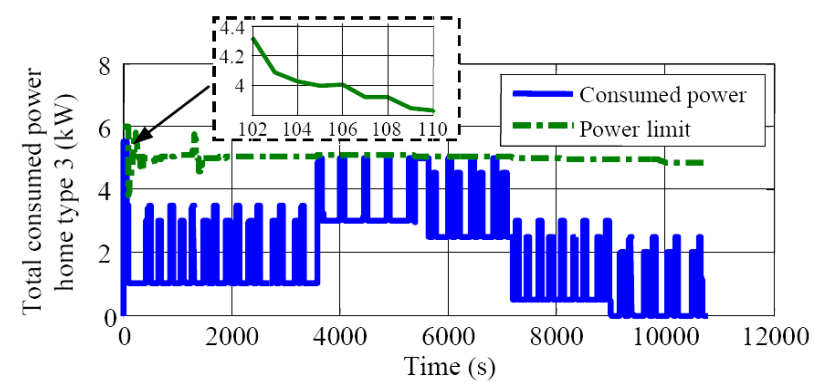

Fig. 9. Load behaviour of node NU30. 
decreasing it with $5 \%$ each time the network needs to shed load. The load management system is aware of the modification brought over to this limit, and modifies the operational constraints.

The temperatures in the two rooms of the home are shown in Fig. 10. The radiator in room 1 manages to maintain the temperature between the set values of $19^{\circ} \mathrm{C}$ and $21^{\circ} \mathrm{C}$. There is a brief period of time around $t=500 \mathrm{~s}$, when the radiator does not manage to lift the room's temperature to $21^{\circ} \mathrm{C}$, because the load management system directs the available power to the other radiator, in order to maintain the room's temperature between the desired values. However, the radiator in the second room does not manage to maintain the temperature during the entire period of simulation.

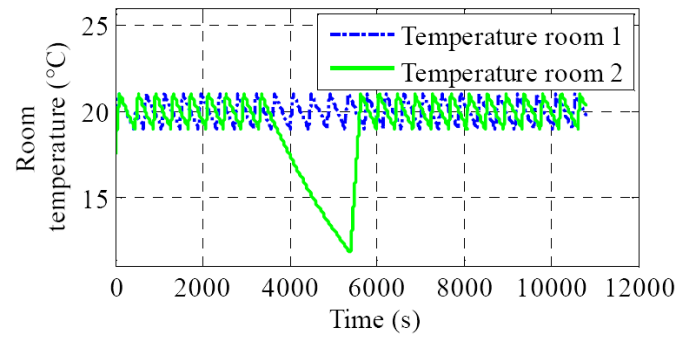

Fig. 10. Room temperature in a type 3 "intelligent" home.

As shown in the Fig. 10, the room temperature level suddenly drops to near $12^{\circ} \mathrm{C}$ at $\mathrm{t}=3600$ s until $\mathrm{t}=5400 \mathrm{~s}$. The explication consists in the way the IHMS operates: during this time interval, two of the non-interruptible loads of the home operate, thus, leaving enough power for only the one radiator to operate. We must take into consideration the fact that in the occurrence of a black-out, the consumers supply would have been ceased, and the thermal comfort would have suddenly worsened. With the SLS procedure and the IHMS implemented, a minimal comfort of consumers is ensured, and the partial black-out of the area is avoided.

As shown above, the implementation of the load management system, brought benefits to the comfort of consumers during periods of network instability. It ensured a proper use of electrical energy within the household, and was a complementary service to the SLS procedure that has been applied.

To conclude, the SLS and the load management system managed to avoid the considered black-out, but, with the expense of dividing the network. Nevertheless, no consumer was put into dark, which was the purpose of the method.

\section{CONCLUSIONS}

The need for an alternative to the brutal LS led to the concept of "soft" load relieving of consumers. The originality of this concept consists in the fact that it sheds only a small percentage of the consumers' power as to improve the voltage level, thus sharing the effort of load relieving between the members of a larger group, respecting in the same time a minimal comfort of the consumers. The goal is to avoid the occurrence of a system breakdown.
In further works, the implementation of the optimal LS will be carried out.

\section{ACKNOWLEDGMENT}

The authors would like to thank Ky Le and Tran Quoc Tuan, members of the Grenoble Electrical Engineering Laboratory, for their support in the achievement of the SLS simulation tool by using their "intelligent" load management system.

\section{REFERENCES}

[1] Electricity Transmission Network Management Center, "Electrical Power Systems Safety Handbook" - in French, RTE, Edition 2004.

[2] D. Novosel, "System Blackouts: Description and Prevention", 2004 IEEE International Conference on Electric Utility Deregulation, Restructuring and Power Technologies, April 2004.

[3] W. Lu , Y. Besanger, E. Zamai, D. Radu, "Analysis of Large Scale Blackouts and Recommendations for Prevention" WSEAS Transactions on power systems Issue 7, Volume 1, July 2006, ISSN 1790-5060.

[4] Swiss Federal Office of Energy, "Report on the blackout in Italy on 28 September 2003", S.F.O.E., November 2003.

[5] C. Bulac, M. Eremia, "Power Systems Dynamics" - in Romanian, Pintech, Bucarest 2005.

[6] M. J. Rider, C. A. Castro, V. L. Paucar, A. V. Garcia "Higher Order Interior-Point Method for Minimising Load-Shedding in a Competitive Electric Power Market", IEE Proceedings, Generation, Transmission and Distribution, Vol.151, $n^{\circ} 4$, July 2004.

[7] K. Le, T. Tran-Quoc, N. Hadjsaid, N.T. Nguyen, C. Surdu, JC. Sabonnadiere, C. Kieny, "Load management by optimizing operations of the radiators", Conference on Innovation for Sustainable Production 2008, Bruges, Belgium, 22 - 25 April 2008.

[8] Prabha Kundur et al. , " Definition and Classification of Power System Stability”, IEEE Trans. Power Syst., vol.19 No.2, May 2004.

[9] "Power Systems Load Shedding" - in French. Available: http://www.drire.gouv.fr/paca/energie.

[10] C.W. Taylor, "Concepts of Undervoltage Load Shedding for Voltage Stability", IEEE Transactions on Power Delivery, Vol. 7, No. 2, April 1992.

[11] France Electricity, "EUROSTAG 4.3 - User's guide" - in French, EdF Tractebel, 2004.

[12] S. Karris, "Introduction to Simulink with Engineering Applications", Second Edition, Orchard Publications, 2008.

[13] B. Hunt, R. Lipsman, "A Guide to Matlab: for Beginners and Experienced Users", Cambridge University Press, 2006.

[14] P. Kundur, "Power system control and stability", New York, McGrawHill, Inc., 1994.

[15] Real load evolution. Available: http://www.rte-france.com.

\section{BIOGRAPHIES}

Diana Craciun obtained her Power Engineering diploma, Power Systems specialty, at Polytechnic University of Bucharest in 2006 and her Master of Science degree at Grenoble Electrical Engineering Laboratory (G2ELab), National Polytechnic Institute of Grenoble (Grenoble-INP) in 2007. She is currently completing her PhD in Power Systems G2ELab. Her research interests are power systems operation, security and dynamics.

Stefan Ichim obtained his Power Engineering diploma, Power Systems specialty, at Polytechnic University of Bucharest in 2008 after a preparation stage on black-out prevention at G2ELab. He is currently completing his Master of Science in Power Systems at Polytechnic University of Bucharest. His research interests are power systems operation, security and dynamics.

Yvon Bésanger received the $\mathrm{PhD}$ in Electrical Engineering from the National Polytechnic Institute of Grenoble (Grenoble-INP) in 1996. He is currently Associate Professor at the Engineering School for Energy, Water and Environment (ENSE3) and G2ELab. His research interests are distribution networks operation and reliability, FACTS devices and power system dynamic stability and security. 